\title{
Seismic mapping of subglacial hydrology reveals previously undetected pressurization event
}

\author{
Celeste R. Labedz ${ }^{1}$, Timothy C. Bartholomaus ${ }^{2}$, Jason M. Amundson ${ }^{3}$, Florent Gimbert ${ }^{4}$, \\ Marianne S. Karplus ${ }^{5}$, Victor C. Tsai ${ }^{6}$, Stephen A. Veitch ${ }^{5}$ \\ ${ }^{1}$ Seismological Laboratory, California Institute of Technology, Pasadena, CA, USA. \\ ${ }^{2}$ Department of Earth and Spatial Sciences, University of Idaho, Moscow, ID, USA. \\ ${ }^{3}$ Department of Natural Sciences, University of Alaska Southeast, Juneau, AK, USA. \\ ${ }^{4}$ University of Grenoble Alpes, CNRS, IRD, Institut des Géosciences de l'Environnement (IGE), \\ Grenoble, France. \\ ${ }^{5}$ Department of Earth, Environmental and Resource Sciences, The University of Texas at El \\ Paso, El Paso, TX, USA. \\ ${ }^{6}$ Department of Earth, Environmental and Planetary Sciences, Brown University, Providence, RI, \\ USA.
}

Corresponding author: Celeste R. Labedz (clabedz@caltech.edu)

\section{Key Points:}

- Subglacial water flow generates continuous seismic tremor observable in the power spectra recorded by on-ice seismometers.

- Using a dense array of seismometers to detect glaciohydraulic tremor allows us to map subglacial pressurization in space and time.

- Seismic data indicate pressurization in the upper glacier, particularly near the margins, that was not perceptible in glacier velocity data.

This article has been accepted for publication and undergone full peer review but has not been through the copyediting, typesetting, pagination and proofreading process, which may lead to differences between this version and the Version of Record. Please cite this article as doi: 10.1029/2021JF006406. 


\begin{abstract}
Understanding the dynamic response of glaciers to climate change is vital for assessing water resources and hazards, and subglacial hydrology is a key player in glacier systems. Traditional observations of subglacial hydrology are spatially and temporally limited, but recent seismic deployments on and around glaciers show the potential for comprehensive observation of glacial hydrologic systems. We present results from a high-density seismic deployment spanning the surface of Lemon Creek Glacier, Alaska. Our study coincided with a marginal lake drainage event, which served as a natural experiment for seismic detection of changes in subglacial hydrology. We observed glaciohydraulic tremor across the surface of the glacier that was generated by the subglacial hydrologic system. During the lake drainage, the relative changes in seismic tremor power and water flux are consistent with pressurization of the subglacial system of only the upper part of the glacier. This event was not accompanied by a significant increase in glacier velocity; either some threshold necessary for rapid basal motion was not attained, or, plausibly, the geometry of Lemon Creek Glacier inhibited speedup. This pressurization event would have likely gone undetected without seismic observations, demonstrating the power of cryoseismology in testing assumptions about and mapping the spatial extent of subglacial pressurization.
\end{abstract}

\title{
Plain Language Summary
}

It is important to understand how glaciers are affected by climate change because glaciers contribute to fresh water resources, flood hazards, and sea levels. We want to understand how liquid water moves underneath solid glacier ice, because that water affects how glaciers move, melt, and crack. We put seismometers (the same sensors that detect earthquakes) on an Alaska glacier to detect tiny vibrations from the flowing water below. By observing the changing strength of the vibrations over time and comparing them to the amount of water that goes into and out of the glacier, we mapped where and when the water below the ice was under pressure. When a lake on top of the glacier drained into the water channels below the glacier, we used the seismic data to see that the water became pressurized under half of the glacier. We did not see other obvious signs of pressurization, such as the glacier speeding up dramatically, so we likely would not have known about the pressurization without the seismometers. To get the best understanding of glaciers, scientists need to combine different methods of observation, and this case is an example of why including seismic observations can be very helpful.

\section{Introduction}

Glacier behavior is strongly influenced by subglacial hydrology, which affects processes such as basal motion, melting, fracture, erosion, sediment and nutrient export, ice-ocean interactions, and more (Iken \& Truffer 1997, Motkya et al. 2006, Schoof 2006, Bartholomaus et al. 2011, Lyderson et al. 2014, Slater et al. 2015). However, observations of subglacial hydrologic systems are spatially and temporally limited by the nature of traditional glaciological observations; in situ methods via boreholes sample only single locations (e.g. Hubbard et al. 1995), while methods like ice-penetrating radar sample only single points in time (e.g. Moore et al. 1999). Expanding observational scales of subglacial hydrology is vital to predicting how

This article is protected by copyright. All rights reserved. 
glacial systems will impact humanity through changes in water resources, flood hazards, and sea level.

Measurement of glaciohydraulic tremor, the continuous seismic signal generated by turbulent water flow in a glacier, can improve the spatial and temporal scales of subglacial hydrological observations. By adapting theoretical descriptions of tremor generation from fluvial seismology (Burtin et al. 2008, Burtin et al. 2011, Tsai et al. 2012, Schmandt et al. 2013, Gimbert et al. 2014), glaciohydraulic tremor has already been shown to reveal properties of subglacial hydrologic systems such as water flux (Bartholomaus et al. 2015, Winberry et al. 2009), sediment transport (Gimbert et al. 2016), water pressurization (Gimbert et al. 2016, Lindner et al. 2020, Nanni et al. 2020), water flow source location (Vore et al. 2019, Nanni et al. 2021), and flood front propagation (Eibl et al. 2020). In addition, analysis of tremor signals at glaciers can also be interpreted to locate and describe other glaciohydraulic sources such as moulin activity (Aso et al. 2017, Röösli et al. 2014, Röösli et al. 2016, Lindner et al. 2020) and crack waves in the basal water layer (Gräff et al. 2019). These studies demonstrate the potential power of glaciohydraulic tremor as an observational tool, and the need to explore its utility in a range of contexts and scales in order to best apply it to studies of glacier systems.

In this study, we observe glaciohydraulic tremor at Lemon Creek Glacier, Alaska with a dense array of seismometers (Section 2.1) in order to expand the spatial scale and detail in which subglacial hydrologic properties can be observed continuously in time, and compare it with hydrologic data collected at the glacier (Section 2.2). We process this data to preserve continuous signals (Section 2.3) and compare the observed signal with theoretical models of tremor generation (Section 2.4). We observe different relationships between seismic tremor and water flux across the surface of the glacier and over time during the course of a lake drainage (Section 3). We interpret these observations as glaciohydraulic tremor reflecting the pressurization state of the subglacial system, and conclude that the upper portion of the glacier pressurized during an increase in water flux from the drainage of an ice-marginal lake, but that this pressurization was not accompanied by a significant increase in glacier velocity (Section 4).

\section{Field Instrumentation and Data Analysis Methodology}

\subsection{Field Site and Instrumentation}

In this study, we observe seismic signals at Lemon Creek Glacier, Alaska (Figure 1), an isolated mountain glacier at the southern tip of the Juneau Icefield, on Tlingit lands (Thornton 2012). Lemon Creek Glacier is approximately $6.5 \mathrm{~km}$ long and $1.5 \mathrm{~km}$ wide, is over $300 \mathrm{~m}$ deep at its thickest, has a $3-7^{\circ}$ surface slope, and flows northward at 20-40 m/yr (Thiel et al. 1957 , Pelto et al. 2013, Veitch et al. 2021). The glacier resides at the headwaters of the Lemon Creek drainage. At the head of the glacier, an ice-marginal lake, Lake Linda, fills with melt and rain water in the early summer (2017 volume was approximately $570,000 \mathrm{~m}^{3}$, see Section 2.2 ), before rapidly draining directly into the subglacial hydrologic system. Lake drainages have been observed annually since at least 1967 (Post \& Mayo 1971).

This article is protected by copyright. All rights reserved. 
We use continuous seismic data from 42 single-component FairfieldNodal (now Magseis Fairfield) ZLand nodal seismometers that were buried in surface snow across the glacier from 28 June to 13 July 2017. These and other instrumentation are shown in Figure 1. We deployed 55 nodes sampling at $250 \mathrm{~Hz}$ in an array with 300-400 m spacing, however some gaps appear in the final data due to malfunctioned sensors. We also deployed two Trimble NetRS GPS receivers attached to poles bored into the ice. The GPS data were processed against the UNAVCO Mendenhall AB50 base station using track, which is part of the GAMIT-GLOBK processing software (Chen, 1998).

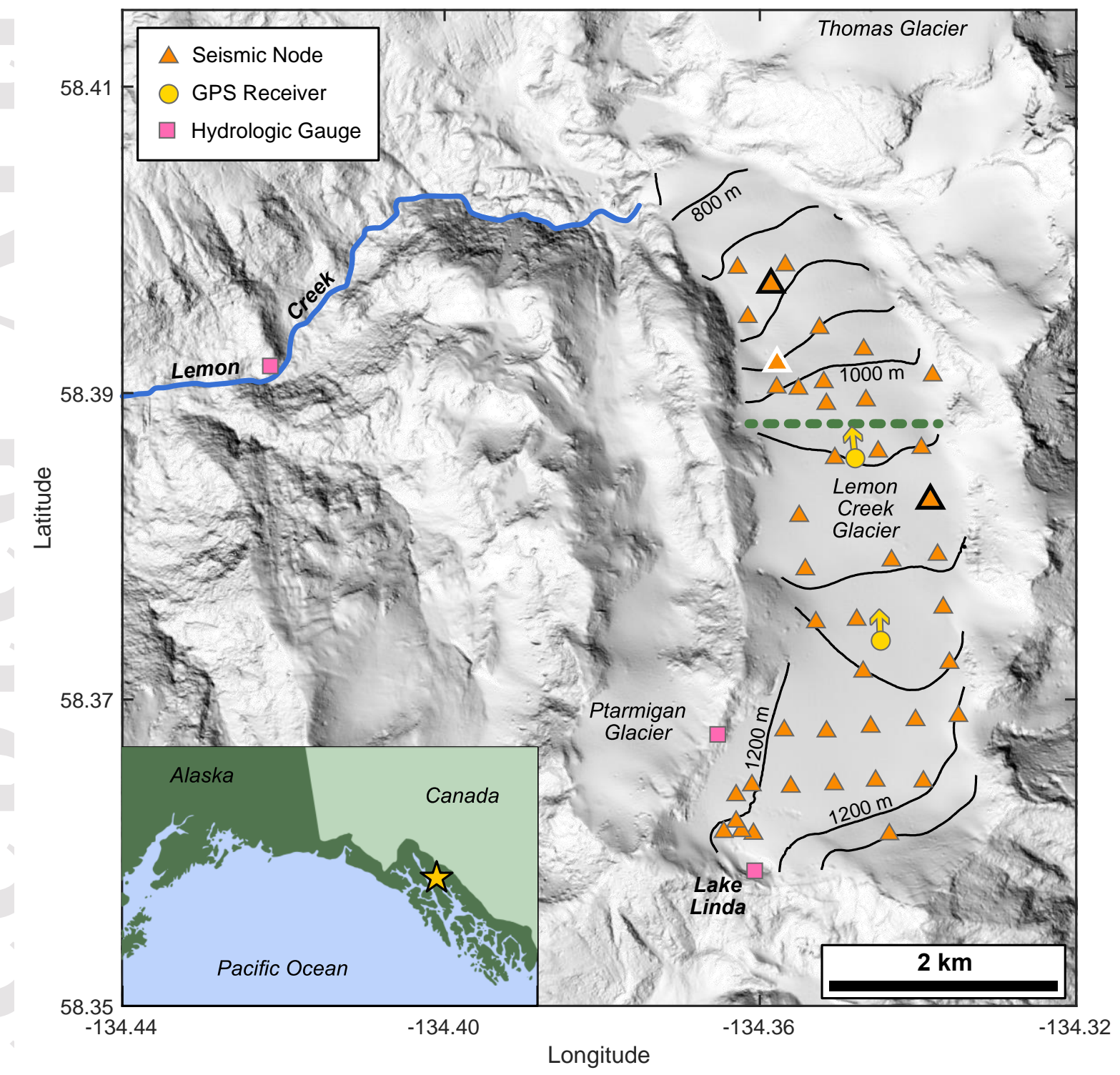

Figure 1. Map of Lemon Creek Glacier, showing glacier surfaces (white), Lake Linda and Lemon Creek (blue), locations of geophysical instrumentation used in this study (seismometers - orange triangles, GPS receivers - yellow circles, hydrologic gauges - pink squares), topography of Lemon Creek Glacier (black lines at $50 \mathrm{~m}$ intervals from $750 \mathrm{~m}$ to $1250 \mathrm{~m}$ ), and approximate location of

This article is protected by copyright. All rights reserved. 
surface slope break (dotted green line). Arrows on GPS receiver icons indicate flow direction. Bold-outlined seismometer icons denote stations used for data displayed in Figure 2 (white outline) and Figure 3 (black outline). Hydrologic gauges are a lake stage gauge (in Lake Linda), rain gauge (west rim of glacier), and USGS stream gauge (on Lemon Creek). Hillshade from ArcticDEM by Polar Geospatial Center (Porter et al 2018). Inset shows location of Lemon Creek Glacier in Southeast Alaska.

\subsection{Discharge Measurements and Modeling}

During our 2017 experiment, we recorded the initial onset of Lake Linda drainage on July 4 with a stage gauge deployed in the lake. This gauge malfunctioned shortly after the drainage began, so the progression of the drainage was then monitored through time-stamped photographs recorded by our field team (Supplemental Figures 1 and 2). The lake drainage rate increased sharply by mid-day on July 5 , and the lake reached its minimum water level by midmorning on July 7 (Supplemental Figure 1). The drained volume was approximately $570,000 \mathrm{~m}^{3}$, calculated with a digital elevation model of the emptied lake basin collected by drone photogrammetry on July 8 , after the drainage was complete (personal communication, Matt Beedle, 2018). This volume of water is equivalent to approximately $6 \mathrm{~cm}$ of rain across the entire surface of the glacier.

Lemon Creek is monitored by a USGS streamflow gauge approximately $3 \mathrm{~km}$ downstream from the toe of the glacier (USGS 2017). This gauge also receives outflow from the smaller Ptarmigan and Thomas glaciers to the west and north of Lemon Creek Glacier, respectively. The volume of the Ptarmigan and Thomas glaciers are likely each an order of magnitude smaller than that of Lemon Creek Glacier based on their relative surface areas (McNeil, 2016), so the outflow $Q$ measured by the streamflow gauge is dominated by the outflow of Lemon Creek Glacier, especially during times of low precipitation and after seasonal snowpack has melted from the lower reaches of the basin.

In order to confirm the reliability of water flux $Q$ recorded at the streamflow gauge as a measure of Lemon Creek Glacier's outflow, we modeled sources of water outfow from the glacier. During our experiment, nearly the entirety of Lemon Creek Glacier was snow covered. To determine the contribution to outflow of snowmelt, we modeled snowmelt from the surface using a degree-day approach [Hock, 2003] driven by air temperatures recorded at a Juneau Icefield Research Program camp, located at 1280 m near the head of Lemon Creek Glacier. We distributed temperatures over an ArcticDEM tile [Porter et al., 2018] using a -0.006 ${ }^{\circ} \mathrm{C} / \mathrm{m}$ lapse rate, and then modeled melt using a $4.5 \mathrm{~mm} / \mathrm{d} /{ }^{\circ} \mathrm{C}$ degree day factor appropriate for snow in maritime climates [Hock, 2003]. During July 3-4, $6 \mathrm{~cm}$ of rain fell at the camp, and the runoff from this event contributes to the flux of Lemon Creek, decreasing over time after the rain ceases. We estimate the decreasing rain runoff contribution to Lemon Creek after this rain event by extrapolating the decrease in water flux at the stream gauge between the end of the rain event and the start of the lake drainage event into a smooth decay to the baseline stream flux observed after the lake drainage event and before the next precipitation event using a cubic smoothing

This article is protected by copyright. All rights reserved. 
spline fit. At the location of the USGS gauge, measured and modeled cumulative runoff are within $5 \%$ of each other (Supplemental Figure 1).

\subsection{Seismic Signal Processing}

We quantify glaciohydraulic tremor from the ambient seismic field at each station by calculating a median power spectral density (PSD), as described in Bartholomaus et al. 2015. In this method, we calculate the PSD (units $(\mathrm{m} / \mathrm{s})^{2} / \mathrm{Hz}$ ) of all consecutive short-duration (30 seconds) waveforms within a long-duration (30 minutes) time window. At a given frequency, we find the median of all power values among the short-duration PSDs. The long-duration median PSD is composed of these individual medians at each frequency value in the spectrum. Because the median PSD method removes the contribution from discrete short-term events as outliers while preserving the contribution from continuous signals, there is no need for prior removal of data segments containing earthquakes, icequakes, or other events. See Supplemental Figure 3 for an example of median PSD processing on a segment of data. We discuss the interpretation of median PSD signals in Section 4. The median PSD of an example station is shown in Figure $2 \mathrm{a}$. Some stations experienced intermittent data quality issues on July 8-10; these data segments clearly contain significant non-natural contributions, which we manually removed after median PSD calculation. These issues occurred around the time that stations were melting out from their burial surface snow, but no causal relationship between the issues and melt-out is clear. In order to determine tremor amplitude (shown in Figure 2b) from the median PSDs, we integrate over a given frequency range to determine the median absolute ground velocity in that range (Press et al. 1988), which is the square root of the signal power as integrated over that range.

\subsection{Source Theory}

Environmental seismic noise has various sources (Larose et al. 2015), but the portion of the ambient seismic field that is attributable to glaciohydraulic tremor in a glacier system can be predicted by adapting theories of tremor generation originally developed for fluvial systems (Tsai et al. 2012, Gimbert et al. 2014). One major source of glaciohydraulic tremor is turbulent water flow. As derived in Gimbert et al. 2016, seismic tremor power $P$ produced by a channel of constant geometry is modeled to increase as a power law with water volume flux $Q$, with the exponent depending on hydraulic regime, as described below. For a channel where changes in $Q$ are driven by changes in hydraulic radius (the cross-sectional area of the flow divided by the wetted perimeter) while hydraulic pressure gradient remains constant, Gimbert et al. 2016 predicts

$$
\text { [1] } \quad P \propto Q^{5 / 4}
$$

For example, this scenario describes a semi-filled channel or a channel freely growing or shrinking to completely accommodate flux changes, Alternatively, for a filled channel where changes in $Q$ are driven by changes in hydraulic pressure gradient, while hydraulic radius remains constant, Gimbert et al. 2016 predicts

$$
\text { [2] } \quad P \propto Q^{14 / 3} .
$$

This article is protected by copyright. All rights reserved. 
Thus, the strength of the scaling between seismic power and water outflow is predicted to depend on the pressurization state; power scales more weakly with flux for a channel with constant pressure gradient and variable hydraulic radius, and it scales more strongly with flux for a channel with constant hydraulic radius and variable pressure gradient. Refer to Figure $3 \mathrm{a}$ for a diagram, and see Gimbert et al. 2016 for full, detailed derivation. These end-member scenarios are theoretical and do not describe every possible source of changing seismic power in a complex environment (e.g. tremor generated during significant co-evolution of both pressure gradient and hydraulic radius), but multiple seismic studies of real glacier systems have observed tremor consistent with these models (Bartholomaus et al. 2015, Gimbert et al. 2016, Vore et al. 2019, Lindner et al. 2020, Nanni et al. 2020).

In order to determine which hydraulic regime appears to dominate the generation of glaciohydraulic tremor detected at any particular station, we compare the water flux $Q$ to the median seismic tremor power $P$ at that station. We use the $1.5-25 \mathrm{~Hz}$ frequency range, where glaciohydraulic tremor is expected to appear when the source-receiver distances are only a few hundred meters (Gimbert et al. 2014, Bartholomaus et al. 2015, Lindner et al. 2020, Nanni et al. 2020). We plot scaled power $\left(P / P_{r e f}\right)$ against scaled discharge $\left(\log \left(Q / Q_{r e f}\right)\right)$, setting the lowest value in the time period of interest as the scaling reference value (as shown in Figure $3 b$ and $3 c$ ), and then use a linear least-squares regression to find the best-fitting slope $b$, representing the exponent in a power-law relationship between tremor and discharge:

[3] $P \propto Q^{b}$.

We then compare the fitted $b$ value to the theoretically predicted relationships (Eq. 1 and Eq. 2) for each subglacial hydrologic regime. Values of $b$ near 5/4 imply variations in tremor generation dominated by changes in hydraulic radius, while values of $b$ near 14/3 imply variations in tremor generation dominated by changes in pressure gradient.

This article is protected by copyright. All rights reserved. 
A

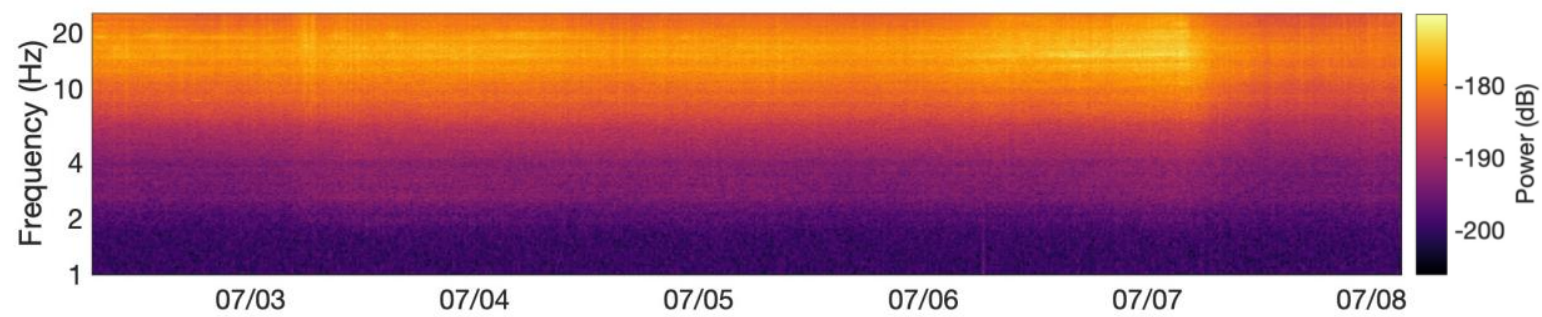

B

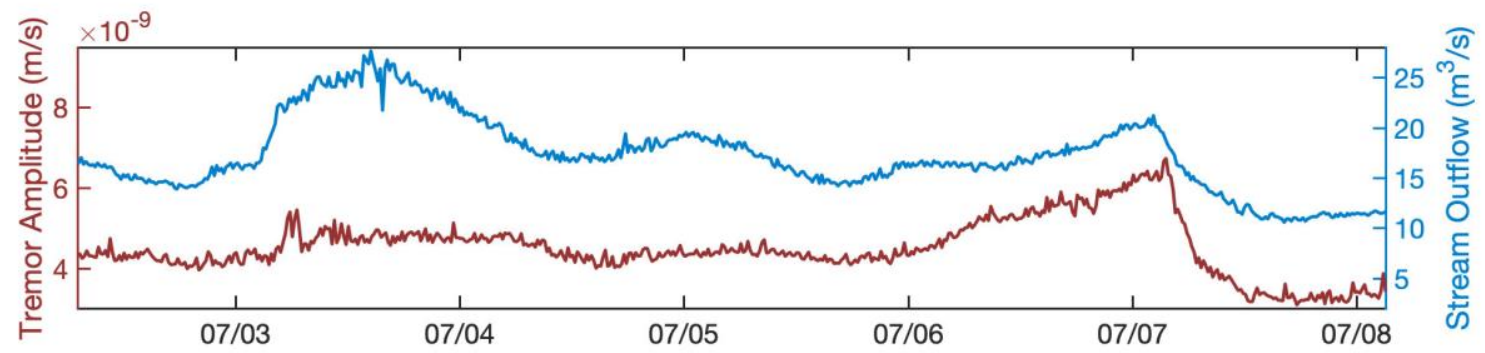

C

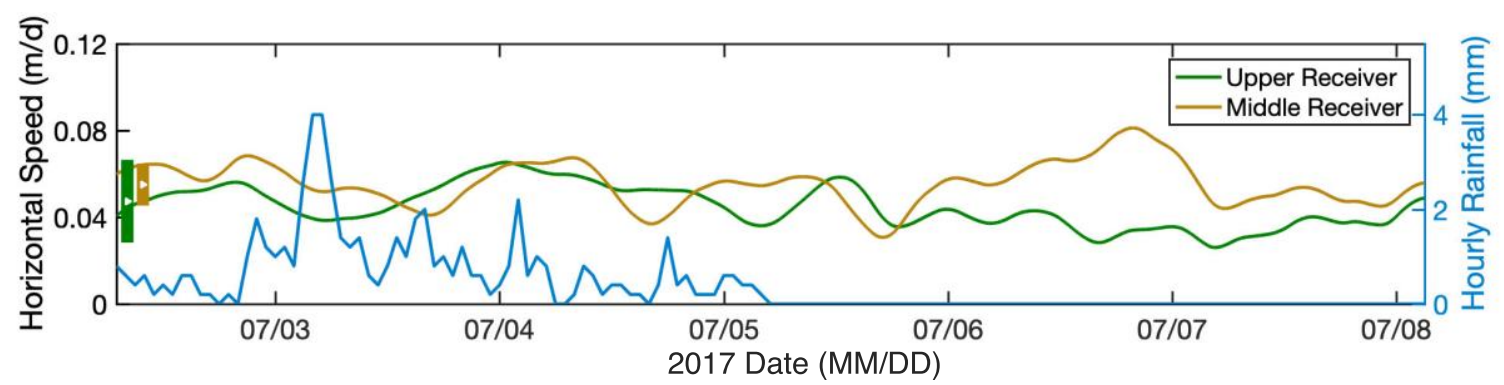

Figure 2. [a] Spectrogram of median power spectral density (PSD) over a logarithmic frequency axis from $1-25 \mathrm{~Hz}$ recorded by one seismometer deployed at Lemon Creek Glacier (outlined in white in Figure 1) during 3-8 July 2017. [b] Median tremor amplitude (red) for the $1.5-25 \mathrm{~Hz}$ range for the same seismometer as in [a], and water flux (blue) recorded at the stream gauge on Lemon Creek. [c] Hourly rainfall (blue) and horizontal speeds of the two GPS receivers deployed on the glacier (green and gold). Vertical bars at left show one standard deviation above and below the mean speed (white triangle).

\section{Results}

Hydrologic activity varied over the course of the seismic deployment; rain fell during 2-4 July, and Lake Linda drained during 5-7 July (see Supplemental Figure 4 for full season precipitation data). We find that the amplitude of ambient seismic tremor in the $1.5-25 \mathrm{~Hz}$ range at seismic nodes also varied over this period, correlating positively with the water flux measured at the USGS gauge, as shown in Figure 2. Seismic tremor power for all stations can be seen in Supplemental Figure 5.

The scaling relationship between the tremor power and water flux (as presented in Section 2.4) varies spatially over the surface of the glacier and temporally during the lake drainage. Tremor power increases throughout July 6 as water flux increases, and then both 
decrease after peak outflow is reached on July 7, as shown in two example stations in Figure $3 b$ and Figure 3c. Records from these two stations differ in their relationships between tremor power and water flux. The station near the middle of the glacier (Figure $3 b$ ) shows a much higher slope before peak outflow than after peak outflow, while the station low on the glacier (Figure 3c) shows similar low slopes for both the rise and fall in water flux. The relationships between seismic tremor power and water flux for more stations can be seen in Supplemental Figure 6.

A
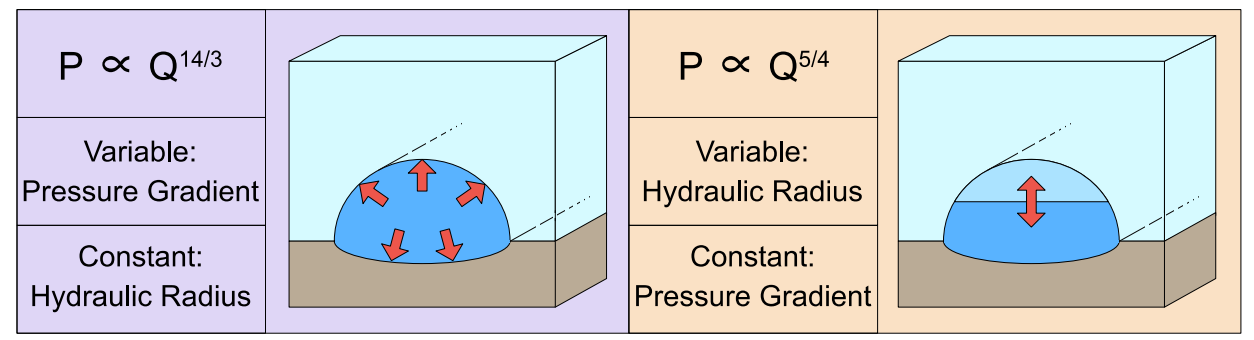

B Middle Glacier Station

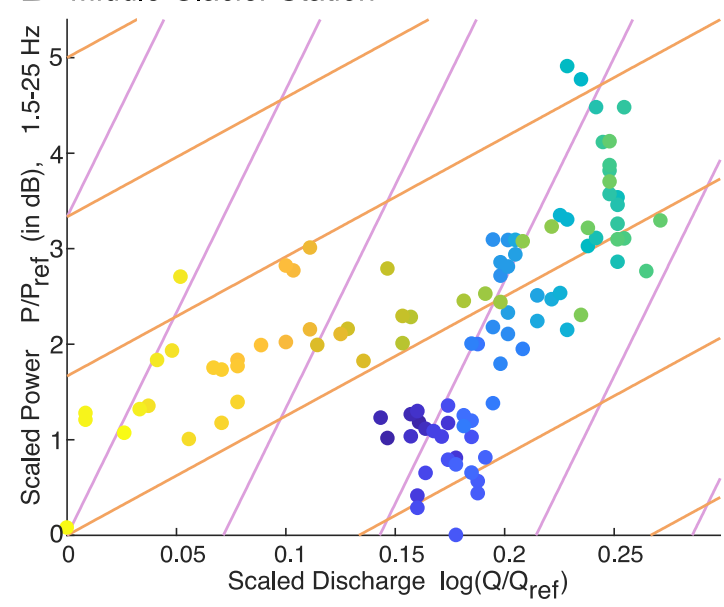

C Lower Glacier Station

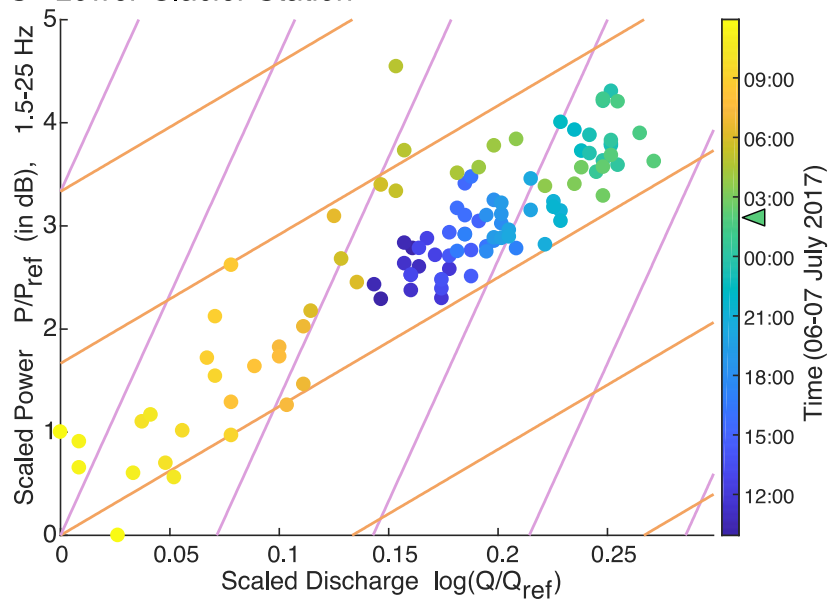

Figure 3. [a] Diagram showing two possible relationships between seismic power and water flux: in purple, a channel with variable pressure gradient and constant hydraulic radius and in orange, a channel with variable hydraulic radius and constant pressure gradient. [b and c] Examples of the relationship between seismic tremor power and water flux over the course of the drainage of Lake Linda for two seismometers (one near the middle of the glacier and one at lower altitude nearer the toe of the glacier, outlined in black in Figure 1). Peak outflow time (02:00 on July 7) is highlighted with the triangle icon on the color bar. Purple lines indicate the slope of a variable pressure gradient system, and orange lines indicate the slope of a variable hydraulic radius system.

During the rising limb of the outburst flood on July 6, stations on different parts of the glacier observe different relationships between tremor power and water flux (Figure 4). We start fitting for the exponent $b$ later than the first onset of the lake drainage, because the stream gauge

This article is protected by copyright. All rights reserved. 
is still receiving rainfall from rapid overland transport from the larger catchment at the initiation of the drainage (see Section 2.2 and Supplemental Figure 1). Using the fitting method described in Section 2.4 for data from 10:00 July 6 to 01:00 July 7, stations on the lower portion of the glacier, north of the slope break at $58.387^{\circ} \mathrm{N}$, observe a median fitted exponent $b$ of 1.391 (interquartile range: $1.151-1.846$ ), while stations on the upper portion of the glacier, south of the slope break, observe a median fitted exponent $b$ of 3.904 (interquartile range: 2.722 - 5.009). During this time period, prior to peak lake drainage and within the upper portion of the glacier, fitted exponents are greater along the east and west margins than they are near the centerline of the upper glacier. Between the peak water flux of the lake drainage at 03:00 July 7 and the end of elevated water flux from the lake drainage at 12:00 July 7, the relationship between tremor power and water flux is much more uniform across the glacier (Figure 4b), with a median fitted exponent of 1.628 (interquartile range 0.515 - 2.403). For comparison, as in Section 2.4, the theoretically modeled exponent for changes in power driven by changes in hydraulic radius is 1.250, and the theoretically modeled exponent for filled channels with changes in power driven by changes in hydraulic pressure gradient is 4.667 .

Flow speeds at the two GPS stations on Lemon Creek Glacier remained remarkably consistent over the measurement period, including during the period of seismometer deployment (see Supplemental Figure 4 for full-season GPS speeds). From July 1 to August 13, the uppermost GPS receiver on the glacier had a mean horizontal speed of $0.047 \mathrm{~m} /$ day (standard deviation $0.019 \mathrm{~m} /$ day) and the GPS receiver on the middle of the glacier had a mean horizontal speed of $0.055 \mathrm{~m} /$ day (standard deviation $0.010 \mathrm{~m} /$ day). The only notable exception to these consistent speeds is a two-day speedup recorded on the upper GPS receiver on July 28-29, during a period of heavy precipitation, with speed peaking at $0.167 \mathrm{~m} /$ day $(6.3$ standard deviations above the mean). During the drainage of Lake Linda, the upper GPS receiver's speed is slightly lower than the mean, within one standard deviation, around and during the lake drainage event. The middle GPS receiver's speed is higher than normal during the lake drainage, reaching 0.080 $\mathrm{m} /$ day (2.5 standard deviations above the mean), but deviations of this magnitude occur at several other times during the deployment. Thus, although the elevated speed at the upper GPS receiver may be a response to the lake drainage, it is difficult to pick out the lake drainage solely from the velocity time series.

This article is protected by copyright. All rights reserved. 

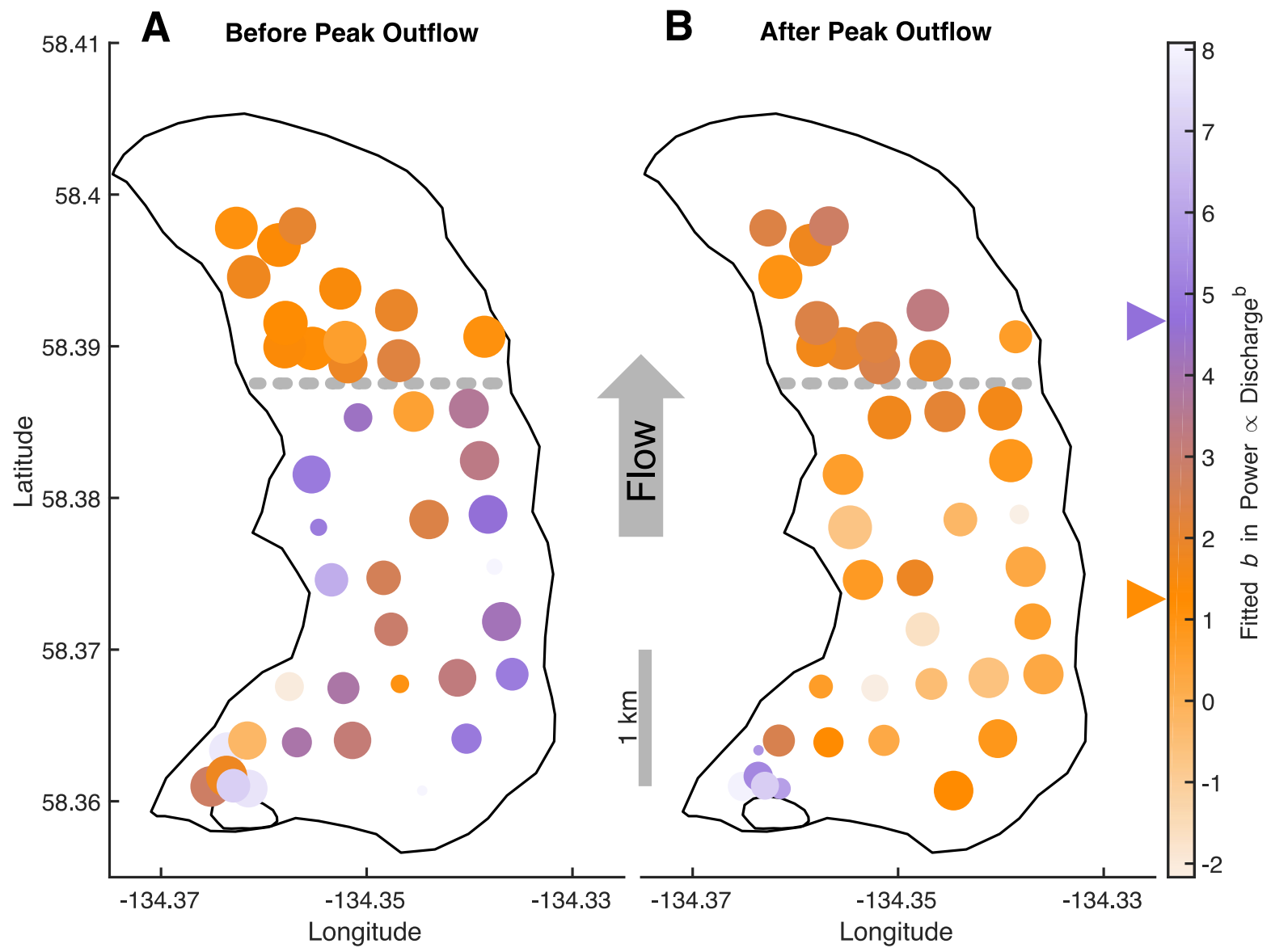

Figure 4. Maps showing fitted exponents $b$, as in the pressure-flux relation $P \propto$ $Q^{b}$ for each station, during the water flux increase before the peak of the lake drainage [a] and during the decrease after the peak [b] over the surface of the glacier, outlined in black. Dotted grey line is the latitude of slope break. Arrows on colorbar denote theoretical $b$ values of $5 / 4$ for the variable hydraulic radius and constant pressure gradient case (orange) and 14/3 for the variable pressure gradient and constant hydraulic radius case (purple) as in Gimbert et al. 2014. Marker size is inversely proportional to standard error of the model fit for $b$ (median standard error: 0.297, minimum: 0.083, maximum 1.437).

\section{Discussion}

Seismic tremor at frequencies between 1.5 and $25 \mathrm{~Hz}$ produced by glaciohydraulic sources is predicted by theory (Gimbert et al. 2014) and detected in other systems (Bartholomaus et al. 2015, Vore et al. 2019, Lindner et al. 2020, Nanni et al. 2020, Eibl et al. 2020). The temporal correlation between water flux through Lemon Creek Glacier and seismic power in these glaciohydraulic tremor frequencies is consistent with the aforementioned literature and leads us to believe that the tremor we report is of dominantly glaciohydraulic origin. The drainage of Lake Linda acts as a natural experiment to support a glaciohydraulic interpretation of

This article is protected by copyright. All rights reserved. 
the seismic signal, as the tremor amplitude positively correlates with the known water input from the lake directly into the subglacial system. The exception to this relationship is the period of rainfall before the lake drainage on July 3-5 (Fig. 2b), when water flux varies much more strongly than tremor amplitude. Relative to the time period containing the drainage of Lake Linda, the weak correlation on July 3-5 is likely due to an overrepresentation in water flux at the stream gauge due to rapid water transport from the non-glacierized portion of the gauge's catchment (approximately equal to the surface area of the glacier). Non-glaciohydraulic explanations of observed seismic tremor, such as earthquake activity, icequake activity, meteorological activity, or human activity are not well supported. No small regional or large global earthquakes are listed in the USGS catalog that would affect ground motion in the frequency range of interest for more than a few seconds at a time, and such short-duration changes are removed as outliers by the median power spectral density process. Local icequakes, while significantly more frequent than earthquakes (small events every few minutes, recorded only at nearby stations), are still infrequent and short-duration enough to be similarly omitted from the median PSD due to the slow velocity of the glacier. See Supplemental Figure 3 for an example of the median PSD process. In addition, icequakes are typically higher in frequency than the tremor we focus on in this study (Röösli et al 2014). The tremor amplitude in this frequency range also does not correlate strongly with meteorological factors such as air temperature or wind activity during the lake drainage (Supplemental Figure 7). Nearby anthropogenic sources of seismic noise, such as the Juneau Icefield Research Program camp's generator, Salmon Creek hydroelectric dam, and mechanical activity in Juneau would theoretically be preserved through the median PSD computation as continuous signals, but we do not observe significant variation in power on the schedules expected from these activities in our frequency range of interest.

In addition to glaciohydraulic tremor generated from water turbulence, as described in Section 2.4, glaciohydraulic tremor can also be generated in subglacial hydrologic systems through bedload saltation of sediment particles (Tsai et al. 2012, Gimbert et al. 2016). We determine that sediment saltation is not likely a significant contributor to the tremor observed at Lemon Creek Glacier by comparing tremor power over time in different portions of the tremor spectrum. The frequency distribution of tremor generated by saltation tends to peak at higher frequencies than tremor generated from water turbulence in the same system (Tsai et al. 2012, Gimbert et al. 2014). This difference creates changes in slope or hysteresis in power between frequency ranges due to changes in scaling between amplitude at different frequencies (Bakker et al. 2020) or due to depletion in sediment supply (Burtin et al. 2008, Roth et al. 2014, Goodling et al. 2018). We found a consistent relationship with no significant hysteresis over the course of the lake drainage event between seismic power in the 1.5-10 Hz range and seismic power in the 10$20 \mathrm{~Hz}$ range (see Supplemental Figure 8). Although the frequency ranges of sediment-generated tremor and turbulence-generated tremor overlap and cannot be completely separated, this relationship between the tested frequency bands suggests that water turbulence is the dominant source of glaciohydraulic tremor in this system. Without clear significant contribution from sediment, we believe the model of tremor generation described in Section 2.4 is most appropriate.

The changing power-law dependence of seismic tremor power on subglacial water flux at each station is consistent with different subglacial pressurization regimes, based on the theoretical relationships described in Section 2.4 from Gimbert et al. 2016. We observe

This article is protected by copyright. All rights reserved. 
significant variation in this power-law dependence over kilometer length scales, and during time intervals prior to and following peak lake drainage (Figure 4); thus, we interpret that our array of nodes and existing seismological theory allow us to map the spatiotemporal variation in subglacial pressurization at kilometer scales across Lemon Creek Glacier. During increasing discharge from the lake, the fitted exponents $b$ for stations across the glacier reveal two distinct regions of subglacial hydrologic behavior (Figure 4). Stations on the lower portion of the glacier observe tremor power that relates to water flux with an exponent similar to that of a theoretical channel system whose changes in tremor are dominated by changes in hydraulic radius (e.g., water flow through unfilled channels at consistent, presumably atmospheric, pressures). On the upper portion of the glacier, however, stations record tremor power that relates to water flux with higher fitted exponents. Many stations' observations are similar to that of a theoretical channel system whose changes in tremor are dominated by changes in pressure gradient, indicating that the subglacial hydrologic system under only the upper portion of the glacier becomes pressurized in response to the rapid influx of water from the lake. This pressurization is presumably strongest within a distributed system more distal from a central conduit axis, in which increases in discharge result in increases in pressure. This interpretation is supported by the larger $b$ values observed near the margins of the upper glacier. The distributed nature of the seismic source and the complex nature of subglacial hydrology mean that any given station is unlikely to contain a perfect record of the idealized end-member models presented in Section 2.4, but we find interpretation at the scales presented here to be reasonable.

For a short period around the time of peak water flux at some stations in the upper portion of the glacier, we observe relationships between tremor power and water flux that are not easily described by either end-member model presented in Section 2.4. For example, in Figure 3 between July $622: 00$ and July 7 02:00, discharge remains nearly constant or increases slightly, while power falls by $1-2 \mathrm{~dB}$. Such behavior can be explained by the co-evolution of both pressure gradient and hydraulic radius, specifically a simultaneous increase in hydraulic radius and decrease in pressure gradient. Indeed, most models of conduit evolution expect that conduit wall melt increases as a function of pressure gradient (Roethlisberger 1972; Werder et al., 2013), thus the pattern shown in Figure $3 \mathrm{~b}$ is expected from the compensation of increasing hydraulic radius maintaining near-steady discharge as the pressure gradient drops. Alternatively, the hydraulic radius could effectively grow through the removal of sediment that potentially obstructs water flow through otherwise efficient conduits. Similar patterns of increasing discharge with falling seismic power are seen in Figure 3b of Gimbert et al., 2016 and interpreted as depressurization.

After peak outflow from the lake has passed and water flux is in decline, stations across the entire surface of the glacier record tremor power that relates to water flux with an exponent near $5 / 4$. These values are predicted for conduits in which changes in water discharge are accommodated by variations in hydraulic radius under a constant pressure gradient, but the different portions of the glacier reach these conditions differently. For the lower portion of the glacier, where the relationship between tremor power and discharge remains consistent for increasing and decreasing discharge (e.g., Figure 3c), subglacial conditions are likely unchanged over the course of the lake drainage. We expect water flow through unfilled channels at consistent, presumably atmospheric, pressures in this area. However, in the upper portion of the glacier, the relationship between tremor power and discharge shows hysteresis, and reflects a regime change in tremor production (e.g., Figure 3b). At these upper glacier sites, we observe

This article is protected by copyright. All rights reserved. 
higher power levels during the falling limb of the event (when slopes are around 5/4) than during the rising limb (when slopes are around 14/3). If the existing pressurized channels were to simply depressurize and carry remaining water as a partially-empty channel, the post-peak power levels would be lower than pre-peak. The counterintuitively higher post-peak power levels we observe could be expected if the channel's cross-sectional area became significantly smaller than during the rising limb of the event while maintaining a high pressure gradient (Gimbert et al. 2016). Such channel shrinkage with higher than atmospheric pressure can occur by creep closure, but even at the maximum ice thickness of the glacier (approximately $350 \mathrm{~m}$ (Veitch et al. 2020)) channel creep closure would take at least four hours from peak water flux (Anderson et al. 2004), and power is already observed as higher than rising-limb levels before this time. Another potential explanation for a change in channel geometry is through movement of sediment. Though we do not expect a large amount of continuously-mobile sediment due to the apparent lack of saltation-generated seismic tremor, some sediment at the beds of subglacial channels is nevertheless reasonable to anticipate. If the high water flux around the peak of the outflow is able to bring new sediment into a channel or redistribute sediment within a channel, that new geometry may be able to generate higher power than on the rising limb of the event as water level falls in the channel. Yet another factor that could drive higher power levels is a change in roughness of the channel walls, with smoother walls generating higher-power tremor through increased flow velocity (Gimbert et al. 2016, Roth et al. 2017). By this mechanism, the observed power levels could be explained by small-scale frictional melt or sediment motion around the peak water flux creating smoother channel walls. More than one of these factors could also contribute in combination to generate the observed tremor behavior on the upper portion of the glacier after pressurization.

The pressurization of at least some portion of Lemon Creek Glacier's subglacial channels during a lake drainage is expected. As water input from the lake rises rapidly, the water flux completely fills existing subglacial channels that earlier in the melt season had only carried smaller, less variable fluxes of rain and meltwater. Thus, lake drainage leads to pressurization and channel growth. As flux from the lake declines after peak lake drainage, the diminishing water ceases to fill now-enlarged channels and the system depressurizes. The geographic boundary between the upper glacier where pressurization is observed and the lower glacier where no pressurization is observed coincides with the glacier's slope break, over which the surface slope more than doubles from $3^{\circ}$ to $7^{\circ}$ and glacier thickness decreases from $300 \mathrm{~m}$ to less than $200 \mathrm{~m}$ (Thiel et al. 1957, Pelto et al. 2013, Veitch et al. 2021). A lack of subglacial pressurization below this slope break may occur because of changes in the character of the glacier that lead to increased efficiency of drainage. First, drainage efficiency in the lower portion of the glacier may be high due to increased channel size. Channels below the slope break may be too large to fill completely during lake drainage, because channels grow larger near glacier termini due to the confluence of tributary channels. Those large channels, created during periods of exceptionally high subglacial water flux (e.g. heavy rain or high melt), can persist over long time scales under thinner ice due to the reduced pressure of closure (Röthlisberger 1972). Second, drainage efficiency below the slope break may also be high due to an increase in the frequency and extent of basal and englacial crevassing from the thinner and faster-flowing ice (Fountain et al. 2005). Third, efficient drainage below the slope break could also be fostered by rapid growth of channels. The growth rate of channel cross-sectional area over time correlates with the hydraulic potential gradient, which increases with bed slope (Werder et al. 2013). Lemon Creek Glacier has low and even reverse bed slopes just above the slope break, but is

This article is protected by copyright. All rights reserved. 
likely to have bed slopes more similar to the surface slope below the slope break, where ice is thin (Thiel et al. 1957, Pelto et al. 2013, Veitch et al. 2021). This steeper gradient potentially leads to more rapid channel expansion below the slope break that could allow the system to drain efficiently without pressurization.

Observational and modeling studies commonly indicate that subglacial hydrologic pressurization necessarily triggers an increase in glacier flow velocity (Iken \& Bindschadler 1986, Iken \& Truffer 1997, Gagliardini et al. 2007, Schoof 2010, Bartholomew et al. 2010), but no remarkable speedup is observed on Lemon Creek Glacier during the drainage of Lake Linda. The speed recorded at the middle GPS receiver during the lake drainage is higher than average (2.5 standard deviations above the mean), but deviations of similar magnitude are recorded at several other times during the deployment, and those deviations are dwarfed by a July 28-29 speedup (6.3 standard deviations above the mean) at the upper GPS receiver associated with a heavy, $6 \mathrm{~cm}$, precipitation event over the entire glacier (see Supplemental Figure 4 for fullseason GPS speeds and rainfall). The sparse GPS coverage in this deployment (only two receivers, both above the slope break) does limit the level of detail with which we can describe glacier motion in this study. Yet, since both receivers are located in the portion of the glacier where pressurization is indicated seismically, we feel reasonably confident in using their recorded speeds to characterize whether or not a notable speedup occurred in conjunction with pressurization.

A lack of major velocity change associated with the lake drainage could be used to suggest that pressurization does not occur and our explanation of glaciohydraulic tremor generation is incomplete in describing the observed seismic signal. However, we argue that pressurization without a significant speedup is entirely reasonable at our field site. First, the drainage of Lake Linda provides only a modest additional flux to the glacier (equivalent to $6 \mathrm{~cm}$ of water averaged over the glacier area, over three days). Such a flux is comparable to many of the rain events that typically occur at our Southeast Alaska field site (see Supplemental Figure 4). Previous modeling work suggests that outburst floods have little impact on glacier flow when the flood discharge is small compared to the background water input to the distal, distributed system (Kingslake and $\mathrm{Ng}, 2013$ ). Additional explanations emerge based again on geometrical reasoning. As discussed earlier, the hydraulic potential gradient is higher below the slope break due to the increased bed and surface slopes. This high potential gradient makes the subglacial drainage system more likely to flow in a channelized, low pressure configuration (Werder et al. 2013), increasing the basal friction in the lower portion of the glacier (Schoof 2005). In this lower region, basal friction remains high throughout the lake drainage because pressurization is only observed in the seismic data in the upper portion of the glacier. Because of its high basal friction and lack of pressurization, we argue that the portion of glacier below the slope break could remain at a stable flow velocity despite the lake drainage. The upper portion of the glacier may experience basal conditions conducive to a velocity increase due to pressurization from the lake drainage, but buttressing from the more stable lower portion could prevent a significant speedup of the glacier as a result of strong longitudinal coupling to the ice below the slope break (Jansson 1997). Though in many cases the pressurization-velocity assumption is reliable, this study suggests that whether subglacial pressurization necessarily produces a significant velocity increase is also dependent on more global controls, such as glacier geometry.

This article is protected by copyright. All rights reserved. 


\section{Conclusions}

Here we demonstrate the utility of seismic data in observing the local subglacial pressurization state of a glacier system by using a hydraulic transient event as a natural experiment. By observing the change in seismic tremor power with respect to subglacial water flux, we observe that the increase in water flux from the drainage of Lake Linda appears to pressurize the subglacial hydrologic system in only the upper portion of Lemon Creek Glacier, while the lower portion remains unpressurized throughout the lake drainage event. Thus, our approach provides mapping of the pressurization state at hourly temporal resolution and kilometer-scale spatial resolution through several-hundred-meter thick ice. The distribution of pressurization we observe coincides with a change in the geometry of the glacier, as the division between the two portions occurs at a slope break below which the glacier's geometry is less conducive to pressurization.

By utilizing seismometers for the bulk of our observations, this study provides insight into a subglacial pressurization event that did not lead to a significant velocity change at two GPS receivers above where the pressurization occurred. As pressurization changes are often assumed to result necessarily in major velocity changes, traditional GPS studies would likely have missed this event entirely. Borehole observations could have revealed pressurization in an event like this if the boreholes intersected the subglacial drainage channels, but a seismic array offers similar insights at lower cost and better spatial coverage. Retrieving information about subglacial conditions through seismic data, as in this study, can fill in observational gaps of other glaciological methods, improving our understanding of the dynamic nature of glacier systems.

\section{Acknowledgments}

This work was made possible in part by hard work in the field by Margot Vore, Daniel Bowden, Galen Kaip, and the students and staff of the 2017 Juneau Icefield Research Program. We especially thank Matt Beedle for provision of the photogrammetrically-produced DEM of Lake Linda, following lake drainage. This work was also aided by the advice of Mike Gurnis and Rob Clayton. We thank three anonymous reviewers for their helpful feedback, which improved this paper greatly. This material is based upon work supported by the National Science Foundation Graduate Research Fellowship under Grant No. DGE-1745301. This work was made possible in part by a University of Idaho seed grant, \#FY18-01.

\section{Data Availability}

Seismic and GPS data used in this manuscript are available at http://dx.doi.org/10.22002/D1.2078

Weather data are available under the Camp 17 station at http://denali.micro-specialties.com/cgibin/uaseaelpDataQuery.cgi 
Discharge data for Lemon Creek are available at

https://waterdata.usgs.gov/ak/nwis/inventory/?site_no $=15052000$

Data processing MATLAB codes are available at http://dx.doi.org/10.22002/D1.9200

\section{References}

Anderson, R. S., Anderson, S. P., MacGregor, K. R., Waddington, E. D., O'Neel, S., Riihimaki, C. A., \& Loso, M. G. (2004). Strong feedbacks between hydrology and sliding of a small alpine glacier. Journal of Geophysical Research: Earth Surface, 109(F3). https://doi.org/10.1029/2004JF000120

Aso, N., Tsai, V. C., Schoof, C., Flowers, G. E., Whiteford, A., \& Rada, C. (2017). Seismologically observed spatiotemporal drainage activity at moulins. Journal of Geophysical Research: Solid Earth, 122(11), 9095-9108. https://doi.org/10.1002/2017JB014578

Bakker, M., Gimbert, F., Geay, T., Misset, C., Zanker, S., \& Recking, A. (2020). Field application and validation of a seismic bedload transport model. Journal of Geophysical Research: Earth Surface, 125(5), e2019JF005416. https://doi.org/10.1029/2019JF005416

Bartholomaus, T. C., Anderson, R. S., \& Anderson, S. P. (2011). Growth and collapse of the distributed subglacial hydrologic system of Kennicott Glacier, Alaska, USA, and its effects on basal motion. Journal of Glaciology, 57(206), 985-1002. https://doi.org/10.3189/002214311798843269

Bartholomaus, T. C., Amundson, J. M., Walter, J. I., O'Neel, S., West, M. E., \& Larsen, C. F. (2015). Sublacial discharge at tidewater glaciers revealed by seismic tremor. Geophysical Research Letters, 42, 6391-6398. https://doi.org/10.1002/2015GL064590

Bartholomew, I., Nienow, P., Mair, D., Hubbard, A., King, M. A., \& Sole, A. (2010). Seasonal evolution of subglacial drainage and acceleration in a Greenland outlet glacier. Nature Geoscience, 3(6), 408-411. https://doi.org/10.1038/ngeo863

Burtin, A., Bollinger, L., Vergne, J., Cattin, R., \& Nábělek, J. L. (2008). Spectral analysis of seismic noise induced by rivers: A new tool to monitor spatiotemporal changes in stream hydrodynamics. Journal of Geophysical Research, 113, B05301.

https://doi.org/10.1029/2007JB005034

Burtin, A., Cattin, R., Bollinger, L., Vergne, J., Steer, P., Robert, A., Findling, N., \& Tiberi, C. (2011). Towards the hydrologic and bed load monitoring from high-frequency seismic noise in a braided river: The "torrent de St Pierre", French Alps. Journal of hydrology, 408(1-2), 43-53. https://doi.org/10.1016/j.jhydrol.2011.07.014

Chen, G. (1998), GPS kinematic positioning for the airborne laser altimetry at Long Valley, California, PhD thesis, Massachusetts Institute of Technology.

This article is protected by copyright. All rights reserved. 
Eibl, E. P., Bean, C. J., Einarsson, B., Pàlsson, F., \& Vogfjörd, K. S. (2020). Seismic ground vibrations give advanced early-warning of subglacial floods. Nature communications, 11(1), $1-11$.

Fountain, A. G., \& Walder, J. S. (1998). Water flow through temperate glaciers. Reviews of Geophysics, 36(3), 299-328. https://doi.org/10.1029/97RG03579

Fountain, A. G., Jacobel, R. W., Schlichting, R., \& Jansson, P. (2005). Fractures as the main pathways of water flow in temperate glaciers. Nature, 433(7026), 618-621. https://doi.org/10.1038/nature03296

Gimbert, F., Tsai, V. C., Amundson, J. M., Bartholomaus, T. C., \& Walter, J. I. (2016). Subseasonal changes observed in subglacial channel pressure, size, and sediment transport. Geophysical Research Letters, 43, 3786-3794. https://doi.org/10.1002/2016GL068337

Gimbert, F., Tsai, V. C., \& Lamb, M. P. (2014). A physical model for seismic noise generation by turbulent flow in rivers. Journal of Geophysical Research: Earth Surface, 119, 2209-2238. https://doi.org/10.1002/2014JF003201

Gagliardini, O., Cohen, D., Råback, P., \& Zwinger, T. (2007). Finite-element modeling of subglacial cavities and related friction law. Journal of Geophysical Research: Earth Surface, 112(F2). https://doi.org/10.1029/2006JF000576

Goodling, P. J., Lekic, V., \& Prestegaard, K. (2018). Seismic signature of turbulence during the 2017 Oroville Dam spillway erosion crisis. Earth Surface Dynamics, 6(2), 351-367. https://doi.org/10.5194/esurf-6-351-2018

Gräff, D., Walter, F., \& Lipovsky, B. P. (2019). Crack wave resonances within the basal water layer. Annals of Glaciology, 60(79), 158-166. https://doi.org/10.1017/aog.2019.8

Hock, R. (2003). Temperature index melt modelling in mountain areas. Journal of hydrology, 282(1-4), 104-115. https://doi.org/10.1016/S0022-1694(03)00257-9

Hubbard, B. P., Sharp, M. J., Willis, I. C., Nielsen, M., \& Smart, C. C. (1995). Borehole waterlevel variations and the structure of the subglacial hydrological system of Haut Glacier d'Arolla, Valais, Switzerland. Journal of Glaciology, 41(139), 572-583. https://doi.org/10.3189/S0022143000034894

Iken, A., \& Bindschadler, R. A. (1986). Combined measurements of subglacial water pressure and surface velocity of Findelengletscher, Switzerland: conclusions about drainage system and sliding mechanism. Journal of Glaciology, 32(110), 101-119. https://doi.org/10.3189/S0022143000006936

Iken, A., \& Truffer, M. (1997). The relationship between subglacial water pressure and velocity of Findelengletscher, Switzerland, during its advance and retreat. Journal of Glaciology, 43(144), 328-338. https://doi.org/10.3189/S0022143000003282

This article is protected by copyright. All rights reserved. 
Jansson, P. (1997). Longitudinal coupling in ice flow across a subglacial ridge. Annals of Glaciology, 24, 169-174. https://doi.org/10.3189/S026030550001212X

Kingslake, J., \& Ng, F. (2013). Modelling the coupling of flood discharge with glacier flow during jökulhlaups. Annals of Glaciology, 54(63), 25-31.

https://doi.org/10.3189/2013AoG63A331

Larose, E., Carrière, S., Voisin, C., Bottelin, P., Baillet, L., Guéguen, P., ... \& Massey, C. (2015). Environmental seismology: What can we learn on earth surface processes with ambient noise?. Journal of Applied Geophysics, 116, 62-74. https://doi.org/10.1016/j.jappgeo.2015.02.001

Lindner, F., Walter, F., Laske, G., \& Gimbert, F. (2020). Glaciohydraulic seismic tremors on an Alpine glacier. The Cryosphere, 14(1), 287-308. https://doi.org/10.5194/tc-14-287-2020

Lydersen, C., Assmy, P., Falk-Petersen, S., Kohler, J., Kovacs, K. M., Reigstad, M., ... \& Zajaczkowski, M. (2014). The importance of tidewater glaciers for marine mammals and seabirds in Svalbard, Norway. Journal of Marine Systems, 129, 452-471. https://doi.org/10.1016/j.jmarsys.2013.09.006

McNeil, C. (2016). Surface mass balance reanalysis of Taku and Lemon Creek glaciers, Alaska: 1946-2015. Doctoral dissertation, Alaska Pacific University.

Moore, J. C., Pälli, A., Ludwig, F., Blatter, H., Jania, J., Gadek, B., Glowacki, P., Mochnacki, D., \& Isaksson, E. (1999). High-resolution hydrothermal structure of Hansbreen, Spitsbergen, mapped by ground-penetrating radar. Journal of Glaciology, 45(151), 524-532. https://doi.org/10.3189/S0022143000001386

Motyka, R. J., Truffer, M., Kuriger, E. M., \& Bucki, A. K. (2006). Rapid erosion of soft sediments by tidewater glacier advance: Taku Glacier, Alaska, USA. Geophysical Research Letters, 33(24). https://doi.org/10.1029/2006GL028467

Nanni, U., Gimbert, F., Vincent, C., Gräff, D., Walter, F., Piard, L., \& Moreau, L. (2020). Quantification of seasonal and diurnal dynamics of subglacial channels using seismic observations on an Alpine glacier. The Cryosphere, 14(5), 1475-1496. https://doi.org/10.5194/tc-14-1475-2020

Nanni, U., Gimbert, F., Roux, P., \& Lecointre, A. (2021). Observing the subglacial hydrology network and its dynamics with a dense seismic array. Proceedings of the National Academy of Sciences, 118(28). https://doi.org/10.1073/pnas.2023757118

Pelto, M., Kavanaugh, J., \& McNeil, C. (2013). Juneau icefield mass balance program 19462011. Earth System Science Data, 5(2), 319-330. https://doi.org/10.5194/essd-5-319-2013

Porter, C., Morin, P., Howat, I., Noh, M.-J., Bates, B., Peterman, K., Keesey, S., Schlenk, M., Gardiner, J., Tomko, K., Willis, M., Kelleher, C., Cloutier, M., Husby, E., Foga, S., Nakamura, H., Platson, M., Wethington, M., Williamson, C., Bauer, G., Enos, J., Arnold, G., Kramer, W., Becker, P., Doshi, A., D’Souza, C., Cummens, P., Laurier, F., Bojesen, M.

This article is protected by copyright. All rights reserved. 
(2018). ArcticDEM. Harvard Dataverse, V1, Accessed 2021-04-23.

https://doi.org/10.7910/DVN/OHHUKH

Post, A., \& Mayo, L. R. (1971). Glacier dammed lakes and outburst floods in Alaska (p. 10). Washington, DC: US Geological Survey.

Press, W. H., B. P. Flannery, S. A. Teukolsky, and W. T. Vetterling (1988), Numerical Recipes in C: The Art of Scientific Computing, 1st ed., Cambridge Univ. Press, Cambridge, U. K.

Roth, D. L., Finnegan, N. J., Brodsky, E. E., Cook, K. L., Stark, C. P., \& Wang, H. W. (2014). Migration of a coarse fluvial sediment pulse detected by hysteresis in bedload generated seismic waves. Earth and Planetary Science Letters, 404, 144-153. https://doi.org/10.1016/j.epsl.2014.07.019

Roth, D. L., Finnegan, N. J., Brodsky, E. E., Rickenmann, D., Turowski, J. M., Badoux, A., \& Gimbert, F. (2017). Bed load transport and boundary roughness changes as competing causes of hysteresis in the relationship between river discharge and seismic amplitude recorded near a steep mountain stream. Journal of Geophysical Research: Earth Surface, 122, 1182-1200. https://doi.org/10.1002/2016JF004062

Röthlisberger, H. (1972). Water pressure in intra-and subglacial channels. Journal of Glaciology, 11(62), 177-203. https://doi.org/10.3189/S0022143000022188

Röösli, C., Walter, F., Husen, S., Andrews, L. C., Lüthi, M. P., Catania, G. A., \& Kissling, E. (2014). Sustained seismic tremors and icequakes detected in the ablation zone of the Greenland ice sheet. Journal of Glaciology, 60(221), 563-575. https://doi.org/10.3189/2014JoG13J210

Röösli, C., Walter, F., Ampuero, J. P., \& Kissling, E. (2016). Seismic moulin tremor. Journal of Geophysical Research: Solid Earth, 121(8), 5838-5858. https://doi.org/10.1002/2015JB012786

Shreve, R. L. (1972). Movement of water in glaciers. Journal of Glaciology, 11(62), 205-214. https://doi.org/10.3189/S002214300002219X

Slater, D. A., Nienow, P. W., Cowton, T. R., Goldberg, D. N., \& Sole, A. J. (2015). Effect of near-terminus subglacial hydrology on tidewater glacier submarine melt rates. Geophysical Research Letters, 42(8), 2861-2868. https://doi.org/10.1002/2014GL062494

Schmandt, B., Aster, R. C., Scherler, D., Tsai, V. C., \& Karlstrom, K. (2013). Multiple fluvial processes detected by riverside seismic and infrasound monitoring of a controlled flood in the Grand Canyon. Geophysical Research Letters, 40, 4858-4863. https://doi.org/10.1002/grl.50953

Schoof, C. (2005). The effect of cavitation on glacier sliding. Proceedings of the Royal Society A: Mathematical, Physical and Engineering Sciences, 461(2055), 609-627. https://doi.org/10.1098/rspa.2004.1350

This article is protected by copyright. All rights reserved. 
Schoof, C. (2010). Ice-sheet acceleration driven by melt supply variability. Nature, 468(7325), 803-806. https://doi.org/10.1038/nature09618

St. Lawrence, W., and A. Qamar (1979), Hydraulic transients: A seismic source in volcanoes and glaciers, Science, 203(4381), 654-656, https://doi.org/10.1126/science.203.4381.654

Stearns, L. A., \& Van der Veen, C. J. (2018). Friction at the bed does not control fast glacier flow. Science, 361(6399), 273-277. https://doi.org/10.1126/science.aat2217

Thiel, E., LaChapelle, E., \& Behrendt, J. (1957). The thickness of Lemon Creek Glacier, Alaska, as determined by gravity measurements. Eos, Transactions of the American Geophysical Union, 38, 5, 754-749.

Thornton, T. F. (2012). Haa Léelk'w Has Aaní Saax': Our Grandparents' Names on the Land. Sealaska Heritage Institute and University of Washington Press

Tsai, V. C., Minchew, B., Lamb, M. P., \& Ampuero, J.-P. (2012). A physical model for seismic noise generation from sediment transport in rivers. Geophysical Research Letters, 39, L02404. https://doi.org/10.1029/2011GL050255

U.S. Geological Survey. 2017. National Water Information System, access online 2017 at https://waterdata.usgs.gov/ak/nwis/inventory/?site_no $=15052000$. https://doi.org/10.5066/F7P55KJN

Veitch, S., Karplus, M., Kaip, G., Gonzalez, L., Amundson, J., \& Bartholomaus, T. (2021). Ice thickness estimates of Lemon Creek Glacier, Alaska, from active-source seismic imaging. Journal of Glaciology, 1-9. https://doi.org/10.1017/jog.2021.32

Vore, M. E., Bartholomaus, T. C., Winberry, J. P., Walter, J. I., \& Amundson, J. M. (2019). Seismic Tremor Reveals Spatial Organization and Temporal Changes of Subglacial Water System. Journal of Geophysical Research: Earth Surface, 124(2), 427-446.

Werder, M. A., Hewitt, I. J., Schoof, C. G., \& Flowers, G. E. (2013). Modeling channelized and distributed subglacial drainage in two dimensions. Journal of Geophysical Research: Earth Surface, 118(4), 2140-2158. https://doi.org/10.1002/jgrf.20146

Winberry, J. P., Anandakrishnan, S., \& Alley, R. B. (2009). Seismic observations of transient subglacial water-flow beneath MacAyeal Ice Stream, West Antarctica. Geophysical Research Letters, 36, L11501. https://doi.org/10.1029/2009GL037730

This article is protected by copyright. All rights reserved. 